\title{
Dopamine Uptake through the Norepinephrine Transporter in Brain Regions with Low Levels of the Dopamine Transporter: Evidence from Knock-Out Mouse Lines
}

\author{
José A. Morón, Alicia Brockington, Roy A. Wise, Beatriz A. Rocha, and Bruce T. Hope \\ Behavioral Neuroscience Branch, National Institute on Drug Abuse, National Institutes of Health, Baltimore, Maryland \\ 21224
}

Selective blockers of the norepinephrine transporter (NET) inhibit dopamine uptake in the prefrontal cortex. This suggests that dopamine in this region is normally cleared by the somewhat promiscuous NET. We have tested this hypothesis by comparing the effects of inhibitors selective for the three monoamine transporters with those of a nonspecific inhibitor, cocaine, on uptake of ${ }^{3} \mathrm{H}$-dopamine into synaptosomes from frontal cortex, caudate nucleus, and nucleus accumbens from wild-type, NET, and dopamine transporter (DAT) knock-out mice. Dopamine uptake was inhibited by cocaine and nisoxetine, but not by GBR12909, in frontal cortex synaptosomes from wild-type or DAT knock-out mice. At transporter-specific concentrations, nisoxetine and GBR12909 failed to block dopamine uptake into frontal cortex synaptosomes from NET knock-out mice. The efficacy of cocaine at the highest dose (1 $\mathrm{mm}$ ) was normal in DAT knock-out mice but reduced by $70 \%$ in NET knock-out mice. Nisoxetine inhibited dopamine uptake by
$20 \%$ in caudate and nucleus accumbens synaptosomes from wild-type and DAT knock-out mice but had no effect in those from NET knock-out mice. Cocaine failed to block dopamine uptake into caudate or nucleus accumbens synaptosomes from DAT knock-out mice. Cocaine and GBR12909 each inhibited dopamine uptake into caudate synaptosomes from NET knock-out mice, but cocaine effectiveness was reduced in the case of nucleus accumbens synaptosomes. Thus, whereas dopamine uptake in caudate and nucleus accumbens depends primarily on the DAT, dopamine uptake in frontal cortex depends primarily on the NET. These data underscore the fact that which transporter clears dopamine from a given region depends on both the affinities and the local densities of the transporters.

Key words: nucleus accumbens; caudate; frontal cortex; synaptosomes; nisoxetine; GBR 12909; cocaine
Monoamines have long been thought to play roles in depression. Even though dopamine (DA) is the monoamine most closely associated with reward and affect, the DA hypothesis of depression has received little recent attention because of the success of antidepressant medications that selectively target the norepinephrine transporter (NET) or the serotonin transporter (SERT) with little or no affinity for the dopamine transporter (DAT) (Eriksson, 2000; Gumnick and Nemeroff, 2000; Svensson, 2000). Although antidepressants can be very selective for the NET or the SERT, these transporters are not equally selective for their nominal substrates. The SERT has too weak an affinity to be likely to take up DA at physiological levels (Hoffman et al., 1991), but the NET can transport DA as well as norepinephrine (NE) (Horn, 1973; Raiteri, 1977) and, indeed, has greater affinity for DA than does the DAT itself (Giros et al., 1994; Gu et al., 1994; Eshleman et al., 1999). Indeed, the NET-selective antidepressant desipramine elevates levels of DA as well as NE in the frontal cortex (FCx) (Carboni et al., 1990; Di Chiara et al., 1992; Tanda et al., 1994; Yamamoto and Novotney, 1998), where the NET is more concentrated than the DAT (Moll et al., 2000).

The present study was designed to compare the effects of

\footnotetext{
Received June 28, 2001; revised Oct. 23, 2001; accepted Oct. 31, 2001.

We thank Dr. Marc Caron for providing the knock-out mice and for his critical review of the manuscript.

Correspondence should be addressed to Dr. Bruce T. Hope, Behavioral Neuroscience Branch, National Institute on Drug Abuse, National Institutes of Health, 5500 Nathan Shock Drive, Baltimore, MD 21224. E-mail: bhope@intra.nida.nih.gov. Copyright (C) 2002 Society for Neuroscience $0270-6474 / 02 / 220389-07 \$ 15.00 / 0$
}

blockade of the NET and DAT on DA uptake into synaptosomes prepared from FCx and other DA terminal fields. This assay allows us to dissociate changes in extracellular DA that result from altered DA clearance from changes that result from altered DA release, which can be secondary to elevations in NE or 5-HT (Pozzi et al., 1994, 1999; Matsumoto et al., 1999; Sakaue et al., 2000). We compared the effects of inhibitors for each of the three monoamine transporters: nisoxetine (which selectively blocks the NET), GBR 12909 (which selectively blocks the DAT), and fluoxetine (which selectively blocks the SERT), with the effects of the nonspecific inhibitor cocaine. We contrasted basal DA uptake and drug-induced inhibition of DA uptake into synaptosomes from FCx, where DAT expression is minimal (Freed et al., 1995; Sesack et al., 1998), with uptake into synaptosomes from caudate nucleus, where DAT expression is maximal, and from nucleus accumbens where intermediate levels of the DAT are expressed. In each case, we compared uptake of $\left[{ }^{3} \mathrm{H}\right] \mathrm{DA}$ into synaptosomes from DAT knock-out, NET knock-out, and wild-type mice.

\section{MATERIALS AND METHODS}

Animals. The original breeding pairs from DAT and NET knock-out mice were obtained from the laboratory of Dr. Marc Caron (Duke University Medical Center, Durham, NC). They contained the DNA constructs previously shown to produce genetic deletions of the DAT and NET, respectively (Giros et al., 1996; Rocha et al., 1998; Wang et al., 1999; Xu et al., 2000). These mice were produced from 20 or more generations of backcrossing on to a $129 / \mathrm{SvJ}$ background inbred strain. We used female homozygous mice and their wild-type littermates derived from the crossing of heterozygous breeding pairs. The animals were 
housed (four or five per cage) on a $12 \mathrm{hr}$ light/dark cycle with ad libitum access to water and food. All animal procedures were in compliance with the National Institutes of Health Guide for the Care and Use of Laboratory Animals.

Measurement of $\left[{ }^{3} \mathrm{H}\right] \mathrm{DA}$ uptake into synaptosomes. DA uptake was measured using synaptosomal fractions of tissue pooled from five or six mice for each brain region. Each experiment was repeated three or four times on different days using freshly pooled tissue from five or six mice each time. The mice were killed by decapitation, and their brains were dissected on an ice-cold dish. The FCx samples were cut from the frontal tip of the brain with a razor blade. The caudate and accumbens (Acb) samples were dissected from a $1 \mathrm{~mm}$ coronal slice. The Acb sample included both the core and shell regions.

The pooled tissues from FCx, caudate, and Acb were placed in ice-cold Krebs'-Ringer's solution buffer (in mM: $\mathrm{NaCl} 125, \mathrm{KCl} 1.2, \mathrm{MgSO}_{4} 1.2$, $\mathrm{CaCl}_{2} 1.2, \mathrm{NaHCO}_{3} 22, \mathrm{NaH}_{2} \mathrm{PO}_{4} 1$, and glucose 10 , adjusted to $\mathrm{pH} 7.4$ ) containing $0.32 \mathrm{M}$ sucrose and homogenized using a glass homogenizing tube and a Teflon pestle. The samples were centrifuged for $10 \mathrm{~min}$ at $1000 \times g$, the pellet was discarded, and the remaining supernatant was centrifuged for an additional $15 \mathrm{~min}$ at $16,000 \times \mathrm{g}$. The resulting P2 pellet containing the synaptosomes remained on ice until it was resuspended for the uptake assay.

The synaptosomal uptake assay used in our experiments has previously been described by Morón et al. (1998). The assay was performed in Krebs'-Ringer's buffer containing $0.64 \mathrm{~mm}$ ascorbic acid, $0.8 \mathrm{~mm}$ pargyline, and $0.1 \mu \mathrm{M}\left[{ }^{3} \mathrm{H}\right] \mathrm{DA}(50 \mathrm{Ci} / \mathrm{mmol})$. This concentration of DA $(0.1$ $\mu \mathrm{M}$ ) is the approximate $K_{\mathrm{m}}$ value for DA uptake in brain synaptosomes (Izenwasser et al., 1990, 1994; Elsworth et al., 1993; Copeland et al., 1996). The uptake assay was initiated by the addition of aliquots (FCx: 100-130 $\mu \mathrm{g}$; Acb: $70-100 \mu \mathrm{g}$; caudate: $50-100 \mu \mathrm{g}$ ) of the synaptosomal fraction followed by incubation for $4 \mathrm{~min}$ at $37^{\circ} \mathrm{C}$. Nonspecific uptake and adsorption of $\left[{ }^{3} \mathrm{H}\right] \mathrm{DA}$ was determined by incubation of a parallel set of samples at $4^{\circ} \mathrm{C}$ (the specific monoamine transporters are inactive at this temperature). The assay was terminated by placing the samples on ice and adding $5 \mathrm{ml}$ of ice-cold Krebs'-Ringer's buffer. The synaptosomes were then separated from the assay solution by filtration through Whatman glass microfiber filters $(\mathrm{GF} / \mathrm{C})$, that had been presoaked in $0.1 \%$ polyethylenimine to reduce nonspecific binding, using a Brandel cellharvester filtration apparatus. The synaptosomes, trapped on the filters, were washed twice with $5 \mathrm{ml}$ of ice-cold Krebs'-Ringer's buffer. The filters were placed in scintillation vials, and $3 \mathrm{ml}$ of Bio-Safe II scintillation fluid (Research Products, Mount Prospect, IL) were added to each vial, and the radioactivity was determined by liquid scintillation spectrometry. Under these experimental conditions, total $\left[{ }^{3} \mathrm{H}\right] \mathrm{DA}$ uptake increased linearly with both protein concentration and time over the 4 min incubation period in samples from each of the three brain regions (data not shown).

Protein was measured using the Bio-Rad assay (Hercules, CA). The uptake inhibition curves were obtained by the addition of varying concentrations of the monoamine uptake blockers to the reaction mix. $\mathrm{IC}_{50}$ values were determined using nonlinear curve fitting (Prism 2.0; GraphPad Software, San Diego, CA).

Chemicals. Chemicals and reagents were obtained from the following sources: 7,8-[ $\left.{ }^{3} \mathrm{H}\right] \mathrm{DA}(50 \mathrm{Ci} / \mathrm{mmol})$ from Amersham (Arlington Heights, IL); pargyline hydrochloride and ascorbic acid from Sigma (St. Louis, MO); cocaine hydrochloride from the National Institute on Drug Abuse (Bethesda, MD); and GBR12909 and nisoxetine hydrochloride from Research Biochemicals (Natick, MA).

\section{RESULTS}

DA uptake into synaptosomes from DAT and NET knock-out mice differed as a function of brain structure (Fig. 1). The rate of DA uptake was $0.45 \mathrm{pmol} \cdot \mathrm{min}^{-1} \cdot \mathrm{mg}^{-1}$ into $\mathrm{FCx}$ synaptosomes, $3.44 \mathrm{pmol} \cdot \mathrm{min}^{-1} \cdot \mathrm{mg}^{-1}$ into caudate synaptosomes, and $2.70 \mathrm{pmol} \cdot \mathrm{min}^{-1} \cdot \mathrm{mg}^{-1}$ into Acb synaptosomes. Uptake in FCx synaptosomes was normal in DAT knock-out mice but severely attenuated in NET knock-out mice (Fig. 1). DA uptake was $40 \%$ less in Acb and caudate synaptosomes from NET knock-out mice and was $>70 \%$ less in Acb and caudate synaptosomes from DAT knock-out mice. An overview of the effects of cocaine, nisoxetine, and GBR 12909 is shown in Table 1.

Cocaine inhibited DA uptake into synaptosomes differentially

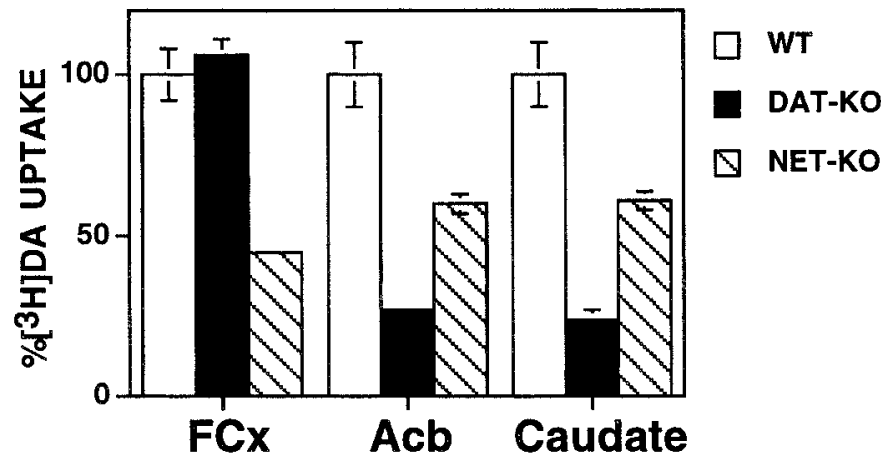

Figure 1. Total $\left[{ }^{3} \mathrm{H}\right] \mathrm{DA}$ uptake in synaptosomes obtained from $\mathrm{FCx}$, Acb, and caudate from DAT knock-out $(D A T-K O)$, NET knock-out (NET-KO), and wild-type (WT) mice. Absolute values for total $\left[{ }^{3} \mathrm{H}\right] \mathrm{DA}$ uptake rates in each genotype of mice are expressed as a percentage of that observed in wild-type mice. Values represent mean \pm SEM obtained from three or four independent experiments using fresh tissue pooled from five or six mice each time.

Table 1. Summary of inhibition of DA uptake by cocaine, nisoxetine, and GBR 12909 in wild-type, DAT, and NET knock-out mice

\section{Inhibition of DA uptake} by cocaine, nisoxetine, and GBR 12909

\begin{tabular}{|c|c|c|c|}
\hline FCx & Wild-type & NET KO & DAT KO \\
\hline Cocaine & 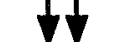 & 0 & 1 \\
\hline $\begin{array}{ll}\text { Nisoxetine } & \text { High } \\
\text { Low }\end{array}$ & $y$ & $\begin{array}{l}0 \\
0\end{array}$ & \\
\hline GBR 12909 & 0 & 0 & N.D. \\
\hline
\end{tabular}

\begin{tabular}{|c|c|c|c|}
\hline Caudate & Wild-type & NET KO & DAT KO \\
\hline Cocaine & 87 & $t+$ & 0 \\
\hline $\begin{array}{ll}\text { Nisoxetine } & \text { High } \\
\text { Low }\end{array}$ & & & $\begin{array}{l}1 \\
0\end{array}$ \\
\hline GBR 12909 & 7 & $\frac{1}{1}+1$ & N.D. \\
\hline
\end{tabular}

\begin{tabular}{|c|c|c|c|}
\hline Acb & Wild-type & NET KO & DAT KO \\
\hline Cocaine & & 17 & 0 \\
\hline $\begin{array}{ll}\text { Nisoxetine } & \text { High } \\
\text { Low }\end{array}$ & & 0 & 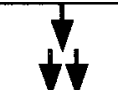 \\
\hline GBR 12909 & $t+1$ & $\downarrow \downarrow t$ & N.D. \\
\hline
\end{tabular}

The arrows “ $\downarrow, \downarrow \downarrow, \downarrow \downarrow \downarrow$ ” qualitatively indicate increasing levels of inhibition in each brain region. "0" indicates DA uptake was insensitive to inhibitor. ND, Not determined. There were both "high"- and "low"-sensitive components of nisoxetinedependent inhibition of DA uptake.

as a function of brain structure and mouse genotype (Fig. 2). The highest concentration of cocaine used $(1 \mathrm{~mm})$ inhibited $50 \%$ of DA uptake into FCx synaptosomes, 90\% of DA uptake into caudate synaptosomes, and $70 \%$ of DA uptake into Acb synaptosomes from wild-type mice. The apparent $\mathrm{IC}_{50}$ values for cocaine-dependent inhibition of DA uptake were $\sim 1 \mathrm{~mm}$ in FCx, $1 \mu \mathrm{M}$ in caudate, and $10 \mu \mathrm{M}$ in Acb synaptosomes. Cocaine blocked DA uptake equally into FCx synaptosomes from both wild-type and DAT knock-out mice but failed to block DA uptake into caudate or Acb synaptosomes from DAT knock-out mice. Cocaine blocked DA uptake equally into caudate synaptosomes 

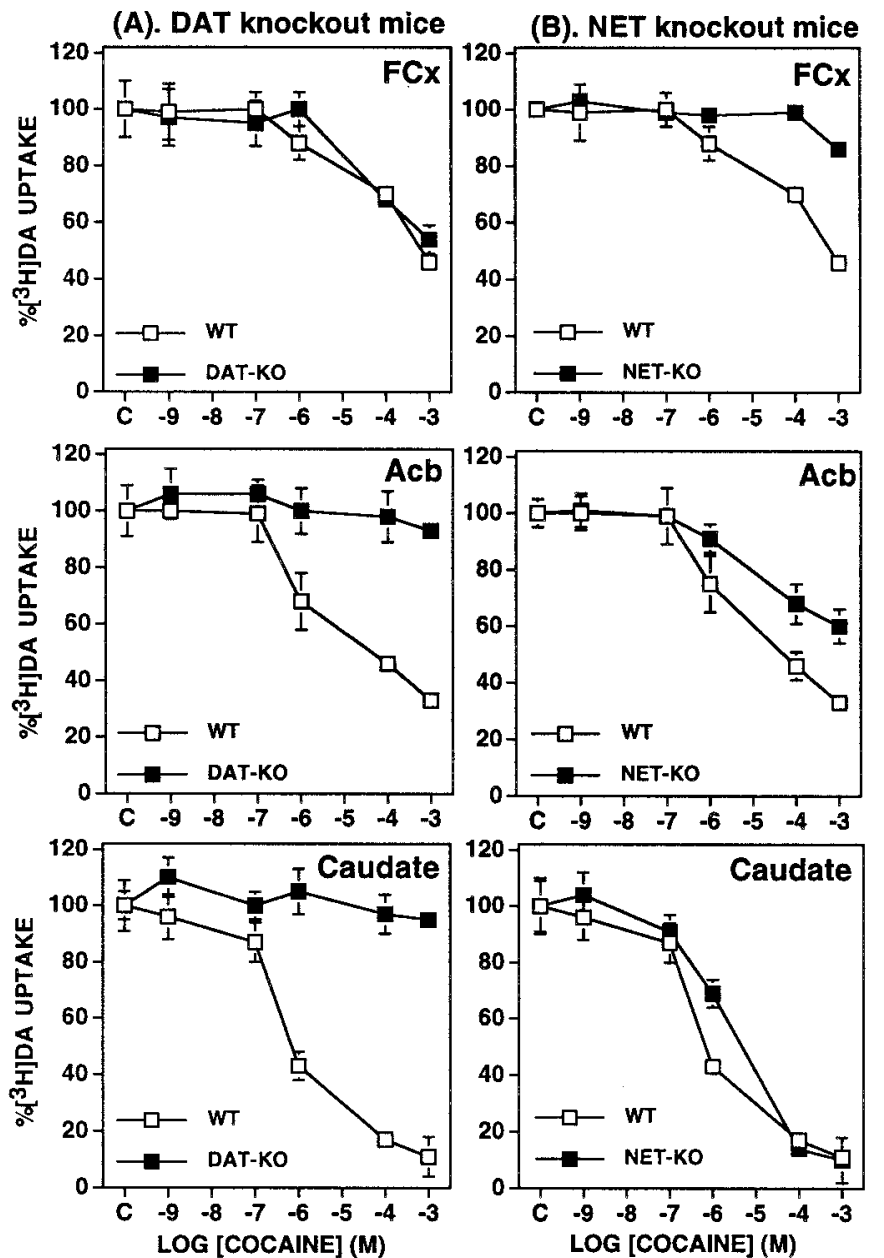

Figure 2. Effects of cocaine on $\left[{ }^{3} \mathrm{H}\right] \mathrm{DA}$ uptake in synaptosomes obtained from FCx, Acb, and caudate from DAT knock-out $(D A T-K O)(A)$, NET knock-out $(N E T-K O)(B)$, and wild-type $(W T)$ mice. The rate of $\left[{ }^{3} \mathrm{H}\right] \mathrm{DA}$ uptake at each concentration of cocaine is expressed as a percentage of that observed for each genotype with only the vehicle present in the assay. Values represent mean \pm SEM obtained from three or four independent experiments using fresh tissue pooled from five or six mice each time.

from wild-type and NET knock-out mice. Cocaine also blocked DA uptake into Acb synaptosomes from NET knock-outs, although there was a decrease in cocaine potency-across the range of doses tested-for inhibition of DA uptake into Acb synaptosomes from NET knock-out mice. Cocaine blocked DA uptake into FCx synaptosomes from wild-type but not from NET knockout mice.

Nisoxetine attenuated DA uptake into wild-type but not NETknock-out synaptosomes from all three regions (Fig. 3). At low concentrations $\left(10^{-9}\right.$ to $\left.10^{-7} \mathrm{M}\right)$, nisoxetine attenuated by $20 \%$ the DA uptake into synaptosomes from each of the three brain regions of wild-type mice. At nonselective concentrations of $10^{-6}$ to $10^{-3} \mathrm{M}$, nisoxetine attenuated DA uptake into synaptosomes from both caudate and Acb of both wild-type and NET knock-out mice. At these higher concentrations, nisoxetine blocked $60 \%$ of the DA uptake into FCx synaptosomes from wild-type mice. Nisoxetine, even at high concentrations, failed to block DA uptake into FCx synaptosomes from NET-knock-out mice.

In the case of DAT-knock-out synaptosomes, nisoxetine blocked DA uptake at both low and high concentrations into
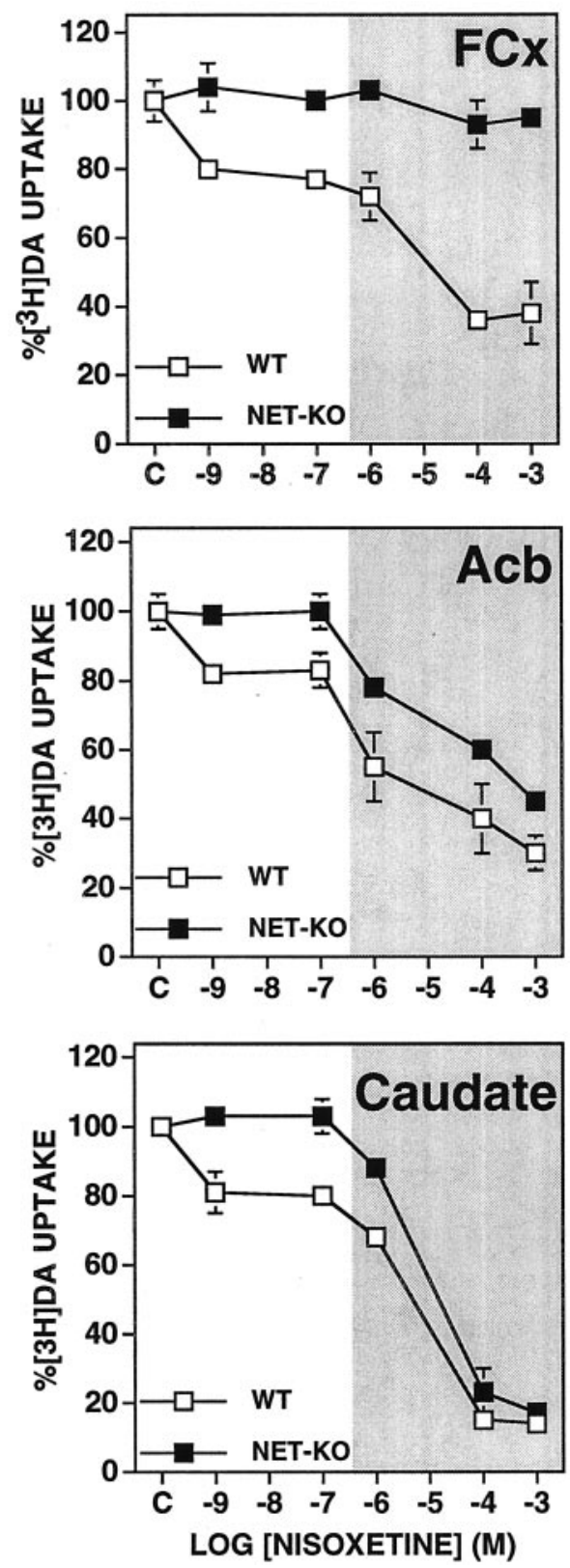

Figure 3. Effects of nisoxetine on $\left[{ }^{3} \mathrm{H}\right] \mathrm{DA}$ uptake in synaptosomes obtained from FCx, Acb, and caudate from NET knock-out (NET-KO) and wild-type $(W T)$ mice. The rate of $\left[{ }^{3} \mathrm{H}\right] \mathrm{DA}$ uptake at each concentration of nisoxetine is expressed as a percentage of that observed for each genotype with only the vehicle present in the assay. Values represent mean \pm SEM obtained from three or four independent experiments using fresh tissue pooled from five or six mice each time. The shaded area indicates the effects of higher nonselective concentrations $(>100 \mathrm{nM})$ of nisoxetine.

synaptosomes from both wild-type and knock-out mice (Fig. 4). At low $\left(10^{-9} \mathrm{M}\right)$ concentration, nisoxetine blocked $\sim 20 \%$ of DA uptake into synaptosomes from each of the three brain regions of both wild-type and DAT knock-out mice. At high concentrations $\left(10^{-6}\right.$ to $\left.10^{-3} \mathrm{M}\right)$, nisoxetine blocked DA uptake by $\sim 60 \%$ in $\mathrm{FCx}$ and Acb synaptosomes from both wild-type and DAT-knock-out mice. At the highest concentrations used $\left(10^{-4}\right.$ and $\left.10^{-3} \mathrm{M}\right)$, nisoxetine blocked uptake into caudate synaptosomes from wildtype, but not from DAT-knock-out mice, by $>80 \%$. 

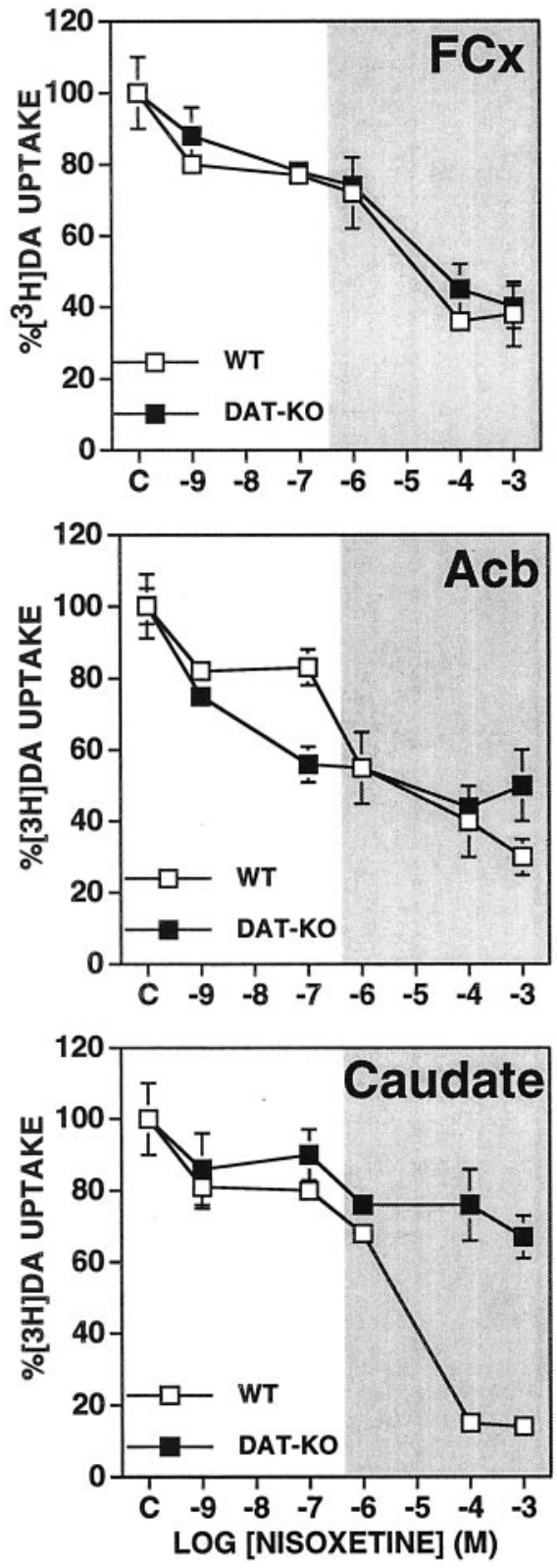

Figure 4. Effects of nisoxetine on $\left[{ }^{3} \mathrm{H}\right] \mathrm{DA}$ uptake in synaptosomes obtained from FCx, Acb, and caudate from DAT knock-out (DAT-KO) and wild-type $(W T)$ mice. The rate of $\left[{ }^{3} \mathrm{H}\right] \mathrm{DA}$ uptake at each concentration of nisoxetine is expressed as a percentage of that observed for each genotype with only the vehicle present in the assay. Values represent mean \pm SEM obtained from three or four independent experiments using fresh tissue pooled from five or six mice each time. The shaded area indicates the effects of higher nonselective concentrations (>100 nM) of nisoxetine.

GBR 12909 blocked DA uptake equally in wild-type and NETknock-out synaptosomes regardless of brain region (Fig. 5). GBR 12909 blocked DA uptake into FCx synaptosomes only at the highest concentration $\left(10^{-3} \mathrm{M}\right)$. At DAT-selective concentrations $\left(10^{-7}\right.$ and $\left.10^{-6} \mathrm{M}\right)$, GBR 12909 blocked $70-80 \%$ of DA uptake into Acb and caudate synaptosomes. Because of the limited productivity of our breeding pairs, the effects of GBR 12909 were not tested on synaptosomes from DAT knock-out mice.

Fluoxetine, a SERT-specific blocker, had no effect on DA uptake into $\mathrm{FCx}$ or caudate synaptosomes from wild-type mice (data not shown).
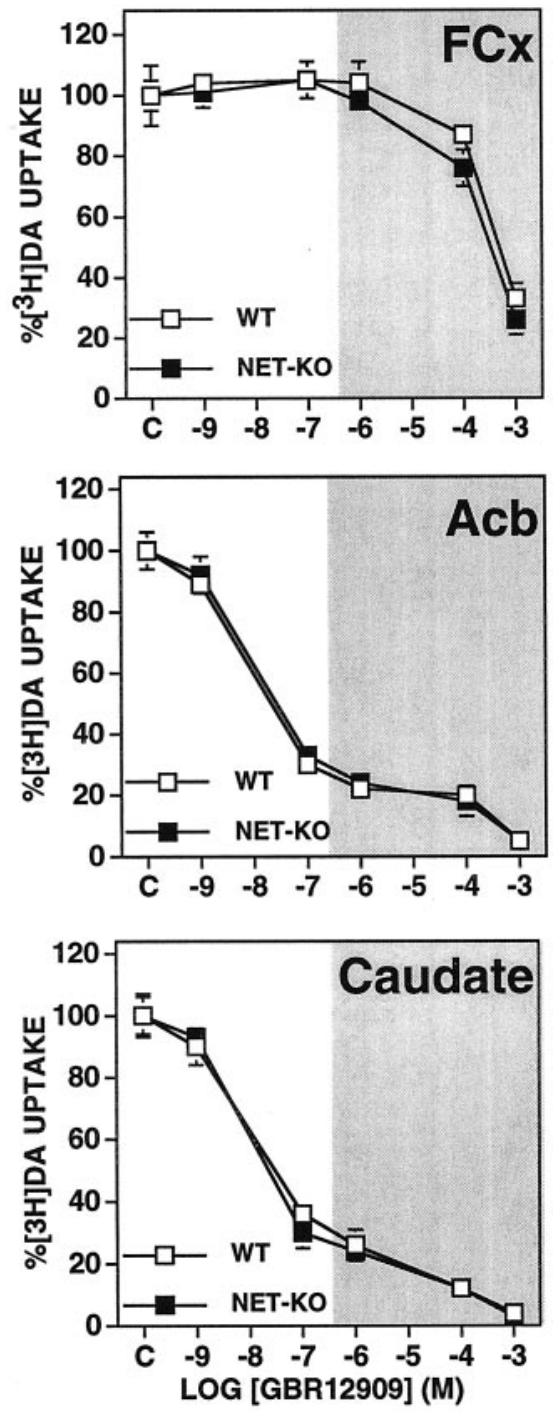

Figure 5. Effects of GBR 12909 on $\left[{ }^{3} \mathrm{H}\right] \mathrm{DA}$ uptake in synaptosomes obtained from FCx, Acb, and caudate from NET knock-out (NET-KO) and wild-type $(W T)$ mice. The rate of $\left[{ }^{3} \mathrm{H}\right] \mathrm{DA}$ uptake at each concentration of GBR 12909 is expressed as a percentage of that observed for each genotype with only the vehicle present in the assay. Values represent mean \pm SEM obtained from three or four independent experiments using fresh tissue pooled from five or six mice each time. The shaded area indicates the effects of nonselective concentrations $(>100 \mathrm{~nm})$ of GBR12909.

\section{DISCUSSION}

\section{DA uptake in FCx}

The present study confirms that extracellular DA is cleared from FCx primarily by the NET. This possibility was first suggested on the basis of microdialysis studies (Carboni et al., 1990; Di Chiara et al., 1992; Tanda et al., 1994; Yamamoto and Novotney, 1998) that did not reveal whether the observed elevations in DA levels were because of clearance of DA by the NET or rather were secondary to a presynaptic action such as that of elevated $\mathrm{NE}$ on DA release (Pozzi et al., 1994). In the present assay, exogenous $\mathrm{NE}$ was not present and thus could not affect the DA nerve terminals. Moreover, DA of intracellular origin, which was unlabeled, could not be confused with the exogenous, labeled, DA of extracellular origin that was taken up by synaptosomes. Furthermore, use of the DAT and NET knock-out mice allowed an 
examination of DA uptake mechanisms under conditions where all contributions of the DAT or NET could be ruled out.

DA uptake into FCx synaptosomes from NET knock-out mice was $55 \%$ lower than those from wild-type mice. This was not a consequence of developmental compensations in the knock-out mice, because nisoxetine, an uptake inhibitor selective for the NET, caused similar inhibition of DA uptake into FCx synaptosomes from wild-type mice. The residual DA uptake into FCx synaptosomes from NET knock-out mice was not because of uptake via the DAT because DA uptake into FCx synaptosomes from NET knock-out mice was not inhibited by selective concentrations of GBR 12909, an uptake inhibitor selective for the DAT. This is consistent with the observation of similar levels of DA uptake into FCx synaptosomes from DAT knock-out mice and wild-type mice. The DAT appears to be ineffective in clearing DA from FCx (Carboni et al., 1990; Di Chiara et al., 1992; Tanda et al., 1994; Yamamoto and Novotney, 1998) because of its sparse concentration (Sesack et al., 1998) relative to the dense concentration of the NET (Schroeter et al., 2000), which has a stronger affinity for DA than does the DAT (Giros et al., 1994; Gu et al., 1994; Eshleman et al., 1999). The rate of DA uptake is so low around the sites of DA release and in the surrounding regions, that DA is able to diffuse to a much larger volume (Stamford et al., 1988; Garris and Wightman, 1994; Cass and Gerhardt, 1995; Jones et al., 1996) where the NET is the predominant transporter capable of transporting DA (Schroeter et al., 2000).

The remaining of DA uptake into FCx synaptosomes from NET knock-out mice is likely attributable to a cocaine-insensitive transporter similar to that observed in rat brain (Izenwasser et al., 1990; Elsworth et al., 1993). Thus, the NET is the only transporter in FCx likely to have mediated the observed cocaine-dependent inhibition of DA uptake into FCx synaptosomes from wild-type and DAT-knock-out mice; cocaine had no effect on DA uptake in FCx synaptosomes from NET knock-out mice. This is consistent with the finding that reverse dialysis of the NET blocker desipramine blocks the increase in DA levels in rat prefrontal cortex after intraperitoneal cocaine administration (Tanda et al., 1997).

\section{DA uptake in caudate}

DA uptake into caudate synaptosomes from DAT knock-out mice was depressed $76 \%$. This was not a consequence of developmental compensations in the knock-out mice, because DAT-selective concentrations of GBR 12909 produced a similar level of inhibition of DA uptake into caudate synaptosomes from wild-type mice. The remaining amount of DA uptake into caudate synaptosomes from DAT knock-out mice was reduced only $20 \%$ by nisoxetine, similar to that in wild-type mice. These results suggest that DA uptake in caudate is mediated primarily by the DAT with only a minor contribution from the NET. This is consistent with the fact that the DAT is abundant and the NET is sparse in caudate (Schroeter et al., 2000). Despite the fact that the NET contributes $20 \%$ of total DA uptake into caudate synaptosomes from DAT knock-out mice, DA uptake via the NET does not appear to play an important role in regulation of DA levels in the intact caudate. Systemic administration or reverse dialysis of desmethyimipramine (DMI) into rat caudate does not significantly increase DA levels in this brain region (Carboni et al., 1990; Di Chiara et al., 1992; Yamamoto and Novotney, 1998). One possibility is that DA is normally intercepted by the DAT, which is located perisynaptically (Nirenberg et al., 1997), before it can reach the higher-affinity but more distant and sparse NET in this brain structure. Even in DAT knock-out mice, the NET does not transport a significant amount of DA in the intact caudate; cyclic voltammetry studies demonstrated that the clearance rate for DA in caudate slices from DAT knock-out mice is similar to the calculated rate for diffusion-mediated clearance and unaffected by the addition of DMI (Jones et al., 1998).

Cocaine-dependent inhibition of DA uptake in caudate seems almost entirely attributable to inhibition of the DAT because cocaine-dependent inhibition of DA uptake into caudate synaptosomes was similar in wild-type and NET knock-out mice but completely absent in DAT knock-out mice. Surprisingly, the NET in caudate synaptosomes from DAT knock-out mice was insensitive to cocaine, whereas it remained somewhat sensitive to nisoxetine.

\section{DA uptake in the nucleus accumbens}

Transporter-specific inhibition of DA uptake into Acb synaptosomes was similar to that into caudate synaptosomes. This result suggests that total DA uptake in our preparations of both the shell and core subregions of Acb combined is mediated mostly by the DAT with a smaller contribution from the NET. However, Acb may not be homogenous in this regard. Reverse dialysis of DMI into the shell subregion of the intact rat Acb increased DA levels (Yamamoto and Novotney, 1998). As with FCx, it remains to be determined whether this DMI-dependent increase in DA was attributable to a decrease in transport through the NET or to noradrenergic interactions with DA terminals. The rightward shift in the dose-response curve for cocaine inhibition of DA uptake into our Acb synaptosomal samples from NET-knock-out mice suggests that the NET can transport a small but significant amount of DA in Acb from wild-type mice. This is consistent with the hypothesis that DMI in the microdialysis studies increased DA levels by directly inhibiting NET-mediated DA uptake, similar to that in FCx. The heterogeneous distribution of the DAT and NET in Acb suggests that the mechanisms for DA transport may vary dramatically depending on the microregion of Acb. The DAT is more densely concentrated in the core subregion than in the shell subregion (Ciliax et al., 1995; Freed et al., 1995; Hersch et al., 1997). The shell subregion itself is divided into patches of densely distributed DAT surrounded by areas with sparse DAT. The NET is present in the shell subregion and distributed along the rostrocaudal axis from low to medium density (Schroeter et al., 2000). Thus, in areas of the shell subregion with sparse DAT and higher levels of the NET, it is possible that DA uptake is locally dependent on the NET.

Cocaine-dependent inhibition of DA uptake into Acb synaptosomes from DAT-knock-out mice was not evident, whereas the dose dependence curve for cocaine-dependent inhibition of DA uptake into Acb synaptosomes from NET knock-out mice was shifted strongly to the right. This suggests that whereas cocainedependent inhibition of DA uptake in Acb is mostly attributable to inhibition of the DAT, inhibition of the NET plays some role, at least in wild-type mice. Indeed, the $20-25 \%$ difference between NET knock-out and wild-type mice for inhibition of DA uptake by $10^{-3} \mathrm{M}$ cocaine was comparable with the $20 \%$ inhibition of DA uptake into Acb synaptosomes from wild-type mice by nanomolar concentrations of nisoxetine.

\section{Differential cocaine-sensitivity between brain regions}

In brain regions where the DAT mediates the majority of DA uptake, such as caudate, DA uptake is highly sensitive to cocaine. In brain regions where the NET mediates the majority of DA uptake, such as FCx, DA uptake has much lower sensitivity to 
cocaine. The NET has been shown to have lower sensitivity to cocaine than the DAT in cell culture (Gu et al., 1994) and in rat brain (Ritz et al., 1990). Thus, the apparent cocaine sensitivity of total DA uptake may decrease in brain regions where the NET mediates the greatest portion of total DA uptake.

Not all DA uptake in the frontal cortex and accumbens was blocked by cocaine. Cocaine-insensitive DA uptake (not inhibited by $10^{-3} \mathrm{M}$ cocaine) may be mediated by the recently cloned and characterized polyspecific cation-monoamine transporters Oct2 and Oct3/EMT, which are found in rat brain (Russ et al., 1996; Busch et al., 1998; Grundemann et al., 1998; Wu et al., 1998). The levels of cocaine-insensitive DA uptake are low. In brain regions where the DAT is abundant and total DA uptake rates are high, such as in caudate, cocaine-insensitive DA uptake does not contribute significantly toward total DA uptake. In brain regions where the DAT and NET are less abundant and total DA uptake rates are low, such as in $\mathrm{FCx}$, cocaine-insensitive DA uptake contributes significantly toward total DA uptake. In our study, only millimolar levels of GBR 12909 could inhibit this cocaineinsensitive transporter.

\section{Potential implications}

The present data underscore the fact that transporter-selective uptake inhibitors are not necessarily transmitter-selective uptake inhibitors. This may explain the fact that cocaine selfadministration, which is well known to be dopamine-dependent (de Wit and Wise, 1977; Roberts et al., 1977) is not lost in DAT knock-out mice (Rocha et al., 1998). For example, cocaine blockade of NET and consequent accumulation of DA in a critical subregion of Acb-presumably some portion of Acb shell (Carlezon et al., 1995)—could account for the rewarding effects of cocaine in these animals (Rocha et al., 1998; Sora et al., 2001). Transporter promiscuity might also explain why NET-selective uptake inhibitors are each effective in treatment of depression (Eriksson, 2000; Gumnick and Nemeroff, 2000; Svensson, 2000); it may be the transmitter, not the transporter, that is critical. Thus, it appears critical to determine transmitter selectivity for a given transporter blocker before assuming that the blocker's effectiveness is mediated by the transporter for which the blocker is most selective.

\section{REFERENCES}

Brown P, Molliver ME (2000) Dual serotonin (5-HT) projections to the nucleus accumbens core and shell: relation of the 5-HT transporter to amphetamine-induced neurotoxicity. J Neurosci 20:1952-1963.

Busch AE, Karbach U, Miska D, Gorboulev V, Akhoundova A, Volk C, Arndt P, Ulzheimer JC, Sonders MS, Baumann C, Waldegger S, Lang F, Koepsell H (1998) Human neurons express the polyspecific cation transporter hOCT2, which translocates monoamine neurotransmitters, amantadine, and memantine. Mol Pharmacol 54:342-352.

Carboni E, Tanda GL, Frau R, Di Chiara G (1990) Blockade of the noradrenaline carrier increases extracellular dopamine concentrations in the prefrontal cortex: evidence that dopamine is taken up in vivo by noradrenergic terminals. J Neurochem 55:1067-1070.

Carlezon Jr WA, Devine DP, Wise RA (1995) Habit-forming actions of nomifensine in nucleus accumbens. Psychopharmacology 122:194-197.

Cass WA, Gerhardt GA (1995) In vivo assessment of dopamine uptake in rat medial prefrontal cortex: comparison with dorsal striatum and nucleus accumbens. J Neurochem 65:201-207.

Ciliax BJ, Heilman C, Demchyshyn L L, Pristupa ZB, Ince E, Hersch SM, Niznik HB, Levey AI (1995) The dopamine transporter: immunochemical characterization and localization in brain. $\mathrm{J}$ Neurosci 15:1714-1723.

Copeland BJ, Vogelsberg V, Neff NH, Hadjiconstantinou M (1996) Protein kinase $\mathrm{C}$ activators decrease dopamine uptake into striatal synaptosomes. J Pharmacol Exp Ther 277:1527-1532.

de Wit H, Wise RA (1977) Blockade of cocaine reinforcement in rats with the dopamine receptor blocker pimozide, but not with the noradrenergic blockers phentolamine or phenoxybenzamine. Can J Psychol 31:195-203.
Di Chiara G, Tanda GL, Frau R, Carboni E (1992) Heterologous monoamine reuptake: lack of transmitter specificity of neuron-specific carriers. Neurochem Int [Suppl]20:231S-235S.

Elsworth JD, Taylor JR, Berger P, Roth RH (1993) Cocaine-sensitive and -insensitive dopamine uptake in prefrontal cortex, nucleus accumbens and striatum. Neurochem Int [Erratum (1995) 26:I] 23:61-69.

Eriksson E (2000) Antidepressant drugs: does it matter if they inhibit the reuptake of noradrenaline or serotonin? Acta Psychiatr Scand [Suppl 402]101:12-17.

Eshleman AJ, Carmolli M, Cumbay M, Martens CR, Neve KA, Janowsky A (1999) Characteristics of drug interactions with recombinant biogenic amine transporters expressed in the same cell type. J Pharmacol Exp Ther 289:877-885.

Freed C, Revay R, Vaughan RA, Kriek E, Grant S, Uhl GR, Kuhar MJ (1995) Dopamine transporter immunoreactivity in rat brain. J Comp Neurol 359:340-349.

Garris PA, Wightman RM (1994) Different kinetics govern dopaminergic transmission in the amygdala, prefrontal cortex, and striatum: an in vivo voltammetric study. J Neurosci 14:442-450.

Giros B, Wang YM, Suter S, McLeskey SB, Pifl C, Caron MG (1994) Delineation of discrete domains for substrate, cocaine, and tricyclic antidepressant interactions using chimeric dopamine-norepinephrine transporters. J Biol Chem 269:15985-15988.

Giros B, Jaber M, Jones SR, Wightman RM, Caron MG (1996) Hyperlocomotion and indifference to cocaine and amphetamine in mice lacking the dopamine transporter. Nature 379:606-612.

Grundemann D, Koster S, Kiefer N, Breidert T, Engelhardt M, Spitzenberger F, Obermuller N, Schomig E (1998) Transport of monoamine transmitters by the organic cation transporter type 2, OCT2. J Biol Chem 273:30915-30920.

Gu H, Wall SC, Rudnick G (1994) Stable expression of biogenic amine transporters reveals differences in inhibitor sensitivity, kinetics, and ion dependence. J Biol Chem 269:7124-7130.

Gumnick JF, Nemeroff CB (2000) Problems with currently available antidepressants. J Clin Psychiatry [Suppl 10]61:5-15.

Hersch SM, Yi H, Heilman CJ, Edwards RH, Levey AI (1997) Subcellular localization and molecular topology of the dopamine transporter in the striatum and substantia nigra. J Comp Neurol 388:211-227.

Hoffman BJ, Mezey E, Brownstein MJ (1991) Cloning of a serotonin transporter affected by antidepressants. Science 254:579-580.

Horn AS (1973) Structure-activity relations for the inhibition of catecholamine uptake into synaptosomes from noradrenergic and dopaminergic neurones in rat brain homogenates. Br J Pharmacol 47:332.

Izenwasser S, Werling LL, Cox BM (1990) Comparison of the effects of cocaine and other inhibitors of dopamine uptake in rat striatum, nucleus accumbens, olfactory tubercle, and medial prefrontal cortex. Brain Res 520:303-309.

Izenwasser S, Terry P, Heller B, Witkin JM, Katz JL (1994) Differential relationships among dopamine transporter affinities and stimulant potencies of various uptake inhibitors. Eur J Pharmacol 263:277-283.

Jones SR, O’Dell SJ, Marshall JF, Wightman RM (1996) Functional and anatomical evidence for different dopamine dynamics in the core and shell of the nucleus accumbens in slices of rat brain. Synapse 23:224-231.

Jones SR, Gainetdinov RR, Wightman RM, Caron MG (1998) Mechanisms of amphetamine action revealed in mice lacking the dopamine transporter. J Neurosci 18:1979-1986.

Matsumoto M, Togashi H, Mori K, Ueno K, Miyamoto A, Yoshioka M (1999) Characterization of endogenous serotonin-mediated regulation of dopamine release in the rat prefrontal cortex. Eur J Pharmacol 383:39-48.

Moll GH, Mehnert C, Wicker M, Bock N, Rothenberger A, Ruther E, Huether G (2000) Age-associated changes in the densities of presynaptic monoamine transporters in different regions of the rat brain from early juvenile life to late adulthood. Dev Brain Res 119:251-257.

Morón JA, Perez V, Fernandez-Alvarez E, Marco JL, Unzeta M (1998) "In vitro" effects of some 5-hydroxy-indolalkylamine derivatives on monoamine uptake system. J Neural Transm 52:343-349.

Nirenberg MJ, Chan J, Pohorille A, Vaughan RA, Uhl GR, Kuhar MJ, Pickel VM (1997) The dopamine transporter: comparative ultrastructure of dopaminergic axons in limbic and motor compartments of the nucleus accumbens. J Neurosci 17:6899-6907.

Pozzi L, Invernizzi R, Cervo L, Vallebuona F, Samanin R (1994) Evidence that extracellular concentrations of dopamine are regulated by noradrenergic neurons in the frontal cortex of rats. J Neurochem 63:195-200.

Pozzi L, Invernizzi R, Garavaglia C, Samanin R (1999) Fluoxetine increases extracellular dopamine in the prefrontal cortex by a mechanism not dependent on serotonin: a comparison with citalopram. J Neurochem 73:1051-1057.

Raiteri M, Del Carmine R, Bertollini A, Levi G (1977) Effect of sympathomimetic amines on the synaptosomal transport of noradrenaline dopamine and 5-hydroxytryptamine. Eur J Pharmacol 41:133-143.

Ritz MC, Cone EJ, Kuhar MJ (1990) Cocaine inhibition of ligand bind- 
ing at dopamine, norepinephrine and serotonin transporters: a structure-activity study. Life Sci 46:635-645.

Roberts DC, Corcoran ME, Fibiger HC (1977) On the role of ascending catecholaminergic systems in intravenous self-administration of cocaine. Pharmacol Biochem Behav 6:615-620.

Rocha BA, Fumagalli F, Gainetdinov RR, Jones SR, Ator R, Giros B, Miller GW, Caron MG (1998) Cocaine self-administration in dopamine-transporter knock-out mice. Nat Neurosci 1:132-137.

Russ H, Staust K, Martel F, Gliese M, Schomig E (1996) The extraneuronal transporter for monoamine transmitters exists in cells derived from human central nervous system glia. Eur J Neurosci 8:1256-1264.

Sakaue M, Somboonthum P, Nishihara B, Koyama Y, Hashimoto H, Baba A, Matsuda T (2000) Postsynaptic 5-hydroxytryptamine(1A) receptor activation increases in vivo dopamine release in rat prefrontal cortex. Br J Pharmacol 129:1028-1034.

Schroeter S, Apparsundaram S, Wiley RG, Miner LH, Sesack SR, Blakely RD (2000) Immunolocalization of the cocaine- and antidepressantsensitive 1-norepinephrine transporter. J Comp Neurol 420:211-232.

Sesack SR, Hawrylak VA, Guido MA, Levey AI (1998) Cellular and subcellular localization of the dopamine transporter in rat cortex. Adv Pharmacol 42:171-174.

Sora I, Hall FS, Andrews AM, Itokawa M, Li Z-F, Wei H-B, Wichems C, Lesch K-P, Murphy DL, Uhl GR (2001) Molecular mechanisms of cocaine reward: Combined dopamine and serotonin transporter knockouts eliminate cocaine place preference. Proc Natl Acad Sci USA 98:5300-5305.
Stamford JA, Kruk ZL, Palij P, Millar J (1988) Diffusion and uptake of dopamine in rat caudate and nucleus accumbens compared using fast cyclic voltammetry. Brain Res 448:381-385.

Svensson TH (2000) Brain noradrenaline and the mechanisms of action of antidepressant drugs. Acta Psychiatr Scand [Suppl 402]101:18-27.

Tanda G, Carboni E, Frau R, Di Chiara G (1994) Increase of extracellular dopamine in the prefrontal cortex: a trait of drugs with antidepressant potential? Psychopharmacology (Berl) 115:285-288.

Tanda G, Pontieri FE, Frau R, Di Chiara G (1997) Contribution of blockade of the noradrenaline carrier to the increase of extracellular dopamine in the rat prefrontal cortex by amphetamine and cocaine. Eur J Neurosci 9:2077-2085.

Wang YM, Xu F, Gainetdinov RR, Caron MG (1999) Genetic approaches to studying norepinephrine function: knock-out of the mouse norepinephrine transporter gene. Biol Psychiatry 46:1124-1130.

Wu X, Kekuda R, Huang W, Fei YJ, Leibach FH, Chen J, Conway SJ, Ganapathy V (1998) Identity of the organic cation transporter OCT3 as the extraneuronal monoamine transporter (uptake2) and evidence for the expression of the transporter in the brain. $\mathrm{J}$ Biol Chem 273:32776-32786.

Xu F, Gainetdinov RR, Wetsel WC, Jones SR, Bohn LM, Miller GW, Wang Y-M, Caron MG (2000) Mice lacking the norepinephrine transporter are supersensitive to psychostimulants. Nat Neurosci 3:465-471.

Yamamoto BK, Novotney S (1998) Regulation of extracellular dopamine by the norepinephrine transporter. J Neurochem 71:274-280. 